\title{
The Research on Customer Satisfaction of Express Service
}

\author{
Wang Xiaobin \\ School of Economic and Management \\ Shenyang Aerospace University \\ Shenyang, China
}

\author{
Liu Chang \\ School of Economic and Management \\ Shenyang Aerospace University \\ Shenyang, China
}

\begin{abstract}
With the continuous development of China's market economy, courier services, the rapid rise of one of the services has become indispensable in our lives. Courier service for its speed, time-consuming short, convenient features popular with users. Courier service companies on China's market is mainly divided into domestic enterprises and foreign enterprises, which the famous express company downwind, Shen Tong, home delivery, tact, etc.; foreign enterprises, foreign giants Fedex Federal Express, DHL and United Parcel Service. Although many courier service, express service quality is good and bad. In recent years, the level of customer courier service there are many views of an exponential rise in the volume of complaints against the courier industry trends. In the above situation, this paper first studies the domestic and international express delivery service industry status quo and the analysis of the development status of the courier service industry. Summed up which are not satisfied with the local courier service as well as ordinary customers courier service, express the development of domestic and foreign, in the form of the questionnaire reflects the true feelings of the clients of the courier service industry, promote the healthy development of the express delivery industry.
\end{abstract}

Keywords-Courier; Services; Customer; Satisfaction

\section{INTRODUCTION}

\section{A. Background and meaning of the paper}

With the rapid development of the global economy and fast-changing of modern science and technology, the logistics industry as an important component of the national economy is developing rapidly worldwide. A new branch - courier services gradually appear in the traditional cargo transportation services. The personalized features of high-efficiency, accuracy, thoughtfulness, speed, high quality are affecting the development trend of modern logistics, and allow modern logistics playing a more important role in global economic development.

Most small and medium courier companies currently are limited to the short-term interests of "limited range of influence"; compete viciously even in the industry or intraarea, be lack of long-term strategic goal planning, rarely develop business-related marketing and service strategies, and does not establish their own brands. Price problems: express has been attracting customers with low cost; with the full range entry of international express giants, intensity of competition will be increased in the industry, and the price does not have an absolute advantage like before. Efficiency is not high. Due to limitations of its own funds and financing difficulties, the problems of poor infrastructure and inefficient management exist in many express enterprises. Most domestic express businesses start from a low base, for example, the staff lack systematic expertise, and the overall quality is not high. Because of the big gap with foreign express delivery companies and large state-owned courier companies in treatment and the working environment, it's difficult to recruit professional logistics talents.

\section{B. Research status both at home and abroad}

Domestic research status: domestic research mainly include the customer satisfaction degree evaluation model conducted in Tsinghua University and improved model of customer satisfaction degree evaluation conducted in Zhongnan University of Economics and Law.

Customer satisfaction studies of logistics enterprise focus on two aspects: considering the content, it mainly concentrates on the customer satisfaction evaluation factors. With the expansion and complexity of logistics enterprises, it involves more factors, in which personalized factors will also appear, so the research need to be further expanded; what's more, models of customer satisfaction evaluation for logistics companies actually used in study are few and far between, and operability is not strong; considering the research methods, questionnaire and data analysis are mainly adopted.

Foreign Research status: the idea of customer satisfaction germinated in Europe, and extensive and indepth research have been done by many scholars after that. The research includes the concept of customer satisfaction, formation mechanism of customer satisfaction, measurement model of customer satisfaction, index model of the customer satisfaction and so on. After the 1990s, the theory of customer satisfaction as new corporate culture and management philosophy became popular in the global business community, and was quickly promoted and applied in developed countries.

Current customer satisfaction studies of logistics enterprises at abroad are mainly the market research analysis, such as the annual investigation of American customer satisfaction and logistics service quality followed by vertical and horizontal analysis. Index systems involved in the course of their investigation and analysis include: service nature, activity performance, reliability, and environmental factors, etc.

\section{STATUS OF EXPRESS DELIVERY DEVELOPMENT.}

Although the start of China's express delivery service industry lags far behind developed countries, with the rapid development of China's national economy, the express industry is constantly growing, occupying most of 
the domestic express business in the market. However, there are also significant problems along with the continuing rapid expansion of express delivery companies in China.

The first problem is price. Express service companies have been attracting customers with low cost; with the full range entry of international express giants, intensity of competition will be increased in the industry, and the price does not have an absolute advantage like before.

Second is the issue of network information. Compared with large foreign express delivery giant, domestic courier companies lack proper network operation and fast query operations, obviously insufficient in terms of networking and information technology, which has a strong impact on their service quality due to lagging quote, inquiries and feedbacks.

The third is the lack of professionals. Most domestic express businesses start from a low base, for example, the staff lack systematic expertise, and the overall quality is not high. Because of the big gap with foreign express delivery companies and large state-owned courier companies in treatment and the working environment, it's difficult to recruit professional logistics talents.

The last is management issues. In the massive expansion of courier service companies, there are serious problems, such as chaotic management, poor management, etc.

\section{ANALYSIS OF CUSTOMER SATISFACTION}

\section{A. Definition of customer satisfaction}

Currently accepted, the first proposing the concept of customer satisfaction is Cardozo, who pioneered the study of the "customer satisfaction" in the marketing field in 1965. He believed that the customer satisfaction will affect customer's subsequent selection and purchase. Customeroriented philosophy of CS plays a huge role in marketing practice, received and adopted by more and more enterprises, and leads to the operation strategies adjustment of a large number of businesses. Up to this day, CS strategy has become the important management philosophy of all types of enterprises, and a magic weapon to market success.

Customer satisfaction in the paper is similar with the view of transaction satisfaction, which refers to the consumer's subjective feelings and evaluation in the process of consumption. It is a more emotional response and closely related with personal circumstances of the customer and product conditions; the main reason it happens is the comparison between customer individual expectations and actual experience before and after consumption; unsatisfied emotions appear when expectations are higher than actual feelings; when expectations are lower than the actual experience, the customers are satisfied and even be loyal after that; when expectation is equal to the actual experience, emotional reactions will be of no difference.

\section{B. Necessity of improving customer satisfaction}

The market is derived from the demand, and the demand constitutes the potential profit of logistics enterprises. The best state of demand activity in the market is satisfaction, so customer satisfaction is the source of the logistics business efficiency. Customer satisfaction management has become the center and the fundamental starting point of logistics business management. Customer satisfaction management is a comprehensive, high-level and high-skill management; customer satisfaction management involves not only the behavior of corporate operations, operational effectiveness, but also involves the concept of enterprise and integrated corporate image. Customer satisfaction not only involves the supply and marketing, but also involves the level of corporate culture. As it were, CS is a set of modern management concept integrating modern idea and methods. Customer satisfaction can be briefly defined as: comparative degree of customer actual experience and their expectations after accepting products and services. This definition reflects both the degree of customer satisfaction and the effectiveness of the products or services provided by the enterprise to meet the needs of the customer.

Improvement of customer satisfaction benefits enterprises with at least the following aspects:

In favor of measuring the quality of business in the past and the current level of operations, and analyzing the gap between competitors and enterprises.

understand the customer's ideas; identify potential customer requirements; fix customer needs, demands and expectations.

Check the company's expectations in order to achieve customer satisfaction and improve customer satisfaction, and be conducive to the development of new quality improvement and business development strategy and objectives.

Enhance profitability.

Identify what the company should do to achieve customer satisfactions in the future; whether we should change the business strategy or business direction.

Measure and seize business opportunities through customer satisfaction; future needs or expectations are the biggest business opportunities.

\section{CUSTOMER SATISFACTION EVALUATION OF COURIER SERVICE}

This chapter will present the survey methodology for the study of the first three chapters - the design and implementation of the survey questionnaire. Questionnaire design and survey are the key to customer satisfaction measurement; the type of questionnaire, questions designed, selection of the survey method are directly related to the accuracy of the evaluation results. Through a rough questionnaire, we will not understand customer true feelings to courier company, and misunderstanding or ambiguity from evaluation issues can lead to distortion or contradictory of data results; follow-up studies will not continue, so well-designed questionnaire is the prerequisite for carrying out customer satisfaction smoothly. In order to enable customers to accurately understand the meaning of each question, and to make the results convenient for statistical data analysis, the chapter describes in detail the questionnaire design, key point, difficulties and details of implementation, and verifies the reliability and validity of questionnaire to ensure the reasonable and effective questionnaire design. 


\section{A. Design principle of questionnaire}

The goal is clear: focus on the survey of customer satisfactions of courier companies, make up questions based on the three-class indicators of the evaluation system; an indicator corresponds to a question, and be purposeful, focused and avoiding repetition.

Rational layout: the order of the problems listed in the questionnaire should be arranged close to the actual process of courier services, that is, the order when customers contact with the courier company, which is in line with the thinking habits of the respondents.

Easy to understand: the questions should be expressed in a common way, easy to understand and answer. For example, the courier company's network coverage should be transformed into question "the delivery scope of courier service" so that respondents of all ages and cultural levels can answer effectively.

Control the amount of questions: the amount of the questionnaire should be within 30 questions, and the completion time should be about 3 minutes. The amount of questions and time are carefully designed for easy answer and readily finishing the survey. Avoid the situation of boredom from respondents due to excessive questions, hasty or perfunctory answers will directly affect the accuracy of the data, and reduce the quality of investigations.

\section{B. Implementation of questionnaire}

The questionnaire in this study consists of two parts: The first part is the customer information, including the age, education, frequency of using courier services and other basic information of respondents. The second part is the main part of the questionnaire, which centers on problems encountered in the implementation process of courier service as well as the customer's true evaluation to the courier company.

\section{Analysis of survey data}

respondent data analysis: the first part of the questionnaire is to understand the personal data of the respondent and find out the customers status and distribution of the courier company. Survey shows that male account for $44.7 \%$ and female account for $55.3 \%$ in the courier company's customers, which is much more balanced and of no significant difference. For ages, customers of 20 - 35 years old are in the majority, which account for $74.6 \%$, followed by customers of more than 35 years old that account for $21.1 \%$, and customers of less than 20 years old account for $4.3 \%$. This is mainly because the delivery goods are usually private or business items; the age of the group using express delivery due to living or working needs is usually above 20 years old. What's more, the rise of online shopping makes the online shopping groups with the age from 20 to 35 become the major courier user, and groups over 35 years old trust more the EMS courier services. Fewer people are willing to change their habits.

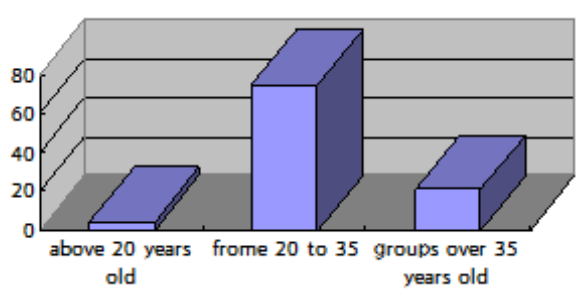

Figure 1. Age distribution of courier users

In the survey, respondents having used courier services more than 3 times account for $65.7 \%$, which means that the user have a better understanding of the service sectors and levels of the company, and these have great help for the completion of the entire questionnaire, making the data descriptions more accurate. In the survey, we also understand that many users will be easily impacted by habit. As long as courier items arrive smoothly, and communicate smoothly with couriers, customers will continue to choose the same courier service, which is very favorable condition for courier companies to develop their own loyal customers. $77.7 \%$ of surveyed customers with college degree and higher education, indicates that the users have better qualities, which also determines that the courier company's customers have a higher requirements and expectations for services.

Summaries of the questionnaire: In addition to the courier company's customer satisfaction index, the paper also analyzed other indicators to the questionnaire. Based on the number of each answer, like "very satisfied, satisfied, general, dissatisfied", calculate the percentage and express directly as shown in figure 4.2. The "very satisfied and satisfied" respondents account for only $27.9 \%$ and the proportion is relatively low, which means that existing customer groups' recognition to the courier service status of the company is not high, so the service level needs to be improved. The "general" respondents account for nearly 40 percent, which means the customer attrition rate of the group is high in face of many courier companies with the same courier business, so close attention and analysis are needed. The "dissatisfied" respondents account for about $25 \%$, and the ratio is large, indicating significant service problems in courier service industry.

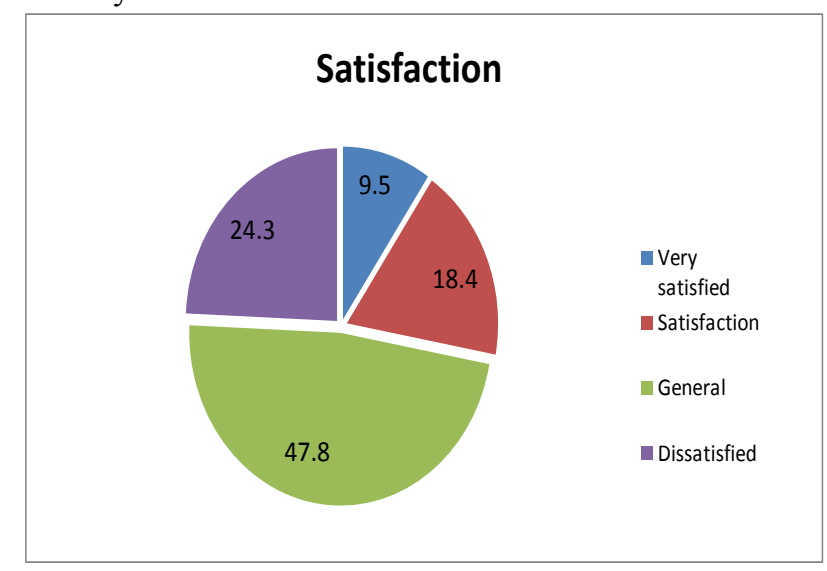

Figure 2. satisfaction degrees to courier service from customers 


\section{CONCLUSION}

In short, in modern society, in spite of the brutal competition in the market and many flaws existed in customer satisfaction of our logistics enterprises, the companies can make use of modern information and communication technologies, grasp the information of customers' needs quickly, hold the customer demand trends, provide timely appropriate products and services to meet customer needs and achieve customer satisfaction, and thus gain a competitive advantage and achieve sustainable and healthy development of business .

\section{REFERENCES}

[1] Li Jinhui, Bao Qiting. How to satisfy your customers. Beijing Diener Market Research, 2007
[2] Yu Chunling, Song Xuebao. Develop effective strategies to remedy mistakes. 2009

[3] Wang Xuping Small tale, big enterprise. Journal of cooperate culture. Issue 12, 2005

[4] Gu Yu. Study on enterprise logistics information system. Market modernization. Issue 12, 2005

[5] Zhang Li Modern enterprise logistics management. China WaterPower Press.2003

[6] Aderson. The antecedents and consequences of customer satisfaction for finns. Marketing Science. 1993, 12(Spring) : 125-126.

[7] Hao-Eft Yang, Chi-Chuan Wu, Kuang-Cheng Wang. An empirical analysis of online game service satisfaction and loyalty[J]. 2009, $36: 1816-1825$.

[8] Gronroos C. An Applied Service Marketing Theory[J]. European Journal of Marketing. 1982, 16(7) : 30-41. 